\title{
Motivating Chinese Students by Fostering Learner Autonomy in Language Learning*
}

\author{
Zejun Ma \\ DaLian University of Technology, Dalian, China \\ Email: mazejun@dlut.edu.cn \\ Ruixue Ma \\ DaLian University of Technology, Dalian, China \\ Email: maruixue@dlut.edu.cn
}

\begin{abstract}
Autonomy in language learning is a relatively new field and research on learner autonomy started in 1970s. However, as the theory and practice of language teaching enters a new century, the importance of helping students become more autonomous in their learning has become one of its more prominent themes. Nowadays, autonomy is widely accepted as a desirable goal in education. A common theme in justifications for autonomy, especially in general education but also in language learning, is that autonomous learners become more highly motivated and that autonomy leads to better, more effective work. This paper is aimed to investigate the link between motivation and learner autonomy, especially how motivation and autonomy can mutually reinforce each other with the emphasis on how the development of learner autonomy through developing negotiated syllabus helps to motivate students in language learning. We trust when we shift the power of making decisions for their own learning through negotiations into students' hands, they will become highly motivated and whole-heartedly involved and take on greater responsibility for their own learning.
\end{abstract}

Index Terms — learner autonomy, motivation, negotiated syllabus, language learning

\section{INTRODUCTION}

Learner autonomy has attracted more and more attention in education especially in the western world since 1970s. Autonomy can be broadly defined as the capacity to take control over one's own learning (Benson 2005, p. 2). As a teacher and researcher who has been involved with the promotion of the idea of autonomy for a number of years, Benson $(2005$, p. 2) claims that autonomous learning is more effective than non-autonomous learning and the development of autonomy implies better language learning. A common theme in justifications for autonomy, especially in general education but also in language learning, is that autonomous learners become more highly motivated and that autonomy leads to better, more effective work (Dickinson 1995, p. 165-74). But how can we motivate learners to be more autonomous? The idea of learner autonomy has been promoted largely by western teachers and academics, will Chinese learners' autonomy be easily fostered and developed in China? How can we motivate Chinese learners to be more autonomous? What is the link between autonomy and motivation? Does motivation lead to learner autonomy or learner autonomy precede motivation? Or can motivation and autonomy mutually reinforce each other? This paper is aimed to investigate the link between motivation and learner autonomy, especially how motivation and autonomy can mutually reinforce each other with the emphasis on how the development of learner autonomy through developing negotiated syllabus helps to motivate students in language learning.

\section{LITERATURE REVIEW}

Autonomy in language learning is a relatively new field and research on learner autonomy started in 1970s. However, as the theory and practice of language teaching enters a new century, the importance of helping students become more autonomous in their learning has become one of its more prominent themes. Nowadays, autonomy is widely accepted as a desirable goal in education, and "few teachers will disagree with the importance of helping learners become more autonomous as learners" (Wenden 1991, p.11). Modern education places great value on the development of the learners' humanistic qualities and "humanistic education is based on the belief that learners should have a say in what they should be learning and how they should learn it, and reflects the notion that education should be concerned with the development of autonomy in the learner" (Nunan 1988, p. 20). Developing from moves towards communicative language teaching, recent innovations in classroom practice have emphasized the value of collaborative learning, learner-centeredness, autonomy and shared decision-making in the classroom. "One corollary of learner-centeredness is that individualization will assume greater importance, as will the recognition that the autonomy of the learner is our

\footnotetext{
* The publication of this paper is supported by "the Fundamental Research Funds for the Central Universities" (DUT10RW413) and (DUT11RW412).
} 
ultimate goal" (Brookes \& Grundy 1988, p.1).

The concept of 'autonomous learning' stemmed from debates about the development of life-long learning skills and the development of independent thinker in 1960s. By 1981 Holec (1981, p. 3) defined autonomy as "the ability to take charge of one's own learning". Dickinson $(1987$, p. 11) accepted the definition of autonomy as "the situation in which the learner is totally responsible for the decisions concerned with his/her learning and the implementation of these decisions". Little (1990, p. 7) suggests that learner autonomy is essentially a matter of the learner's psychological relation to the process and content of learning. In Pennycook's (1997, p. 45) political-critical viewpoint, development of autonomy and agency must involve becoming "an author of one's own world". All the definitions of autonomy entail capacity and willingness on the part of the learner to act independently and in cooperation with others, so as to be a socially responsible person.

A common theme in justifications for autonomy, especially in general education but also in language learning, is that autonomous learners become more highly motivated and that autonomy leads to better, more effective work (Dickinson 1995). Autonomous learners draw on their intrinsic motivation when they accept responsibility for their own learning and commit themselves to developing the skills of reflective self-management in learning. To find the link between motivation and autonomy it is necessary to turn to the literature on motivation in general education, and especially the literature on cognitive motivation (Dickinson 1995).

Motivation is typically defined as the forces that account for the arousal, selection, direction, and continuation of behavior (Biehler 1993, P. 508) and the role of motivation in learning a second/foreign language is one of the important subjects in the study of second language acquisition. In the past decades, researchers have been conducting studies of language learning motivation from different perspectives. Gardner \& Lambert $(1959,1972)$ investigate motivation from socio-psychological perspective. They considered the motivation to learn the language of the other community to be a primary force responsible for enhancing or hindering intercultural communication and affiliation. The current spirit in motivational psychology (and in psychology in general) is characterized by cognitive approach (Dörnyei 2005, p. 10). Current cognitive approaches place the focus on the individual's thoughts, beliefs, and interpretational processes that are transformed into action. The influential cognitive approaches to motivation are: self-determination theory, attribution theory, and goal theories. Deci and Ryan's $(1985,2002)$ self-determination theory has been the most influential approaches in motivational psychology. The main terms associated with self-determination theory are intrinsic and extrinsic motivation. Noels, Luc Pelletier and Robert Vallerand (2000) also specialize in self-determination theory. Their research has provided insights into how the main concepts: intrinsic and extrinsic motivation fit into the L2 field. Attribution theory became the dominant theory in the 1980s. Attribution theory explains how people perceive the causes of their actions and those of others (Weiner, 1985). It manages to link people's past experiences with their future achievement effort by introducing causal attributions as the mediating link. The study of goals within the field of motivation has a long history (Anderman \& Wolters, 2006). Goal-orientation theory is the most prominent area in the study of goals. Goal orientation theorists are concerned with the reasons why students choose to engage in particular tasks. Pintrich and Schunk (2002, p. 242) have recently concluded, "currently, it is probably the most active area of research on student motivation in classroom and it has direct implications for students and teachers."

Whatever is stressed in the cognitive theories of motivation, it can be seen that people are seen as active and curious, searching for information to solve personally relevant problems, which corresponds to the theories of autonomy in language learning The fostering of autonomy requires a focus on the learner's perspective in regard to the goals and process of learning (Benson 2005, P. 20). Noels (2001 b) applies self-determination theory to the examination of the relationship of student autonomy and the language teacher's communicative style. This article has special significance in that it addresses an area, student autonomy and the relationship between learner autonomy and L2 motivation has also been recognized by several scholars (e.g., Spratt, Humphreys, \& Chan, 2002; Ushioda, 1996). The study done by Spratt, Humphreys, \& Chan ( 2002) aimed to assess students' readiness for learner autonomy in language learning by examining their views of their responsibilities and those of their teachers', their confidence in their ability to operate autonomously and their assessment of their level of motivation to learn English. It also investigated their actual practice of autonomous learning in the form of both outside and inside class activities. The findings lead the authors to conclude that motivation is a key factor that influences the extent to which learners are ready to learn autonomously, and that teachers might therefore endeavour to ensure motivation before they train students to become autonomous. Dickinson( 1995, p. 173-4) argues that there is substantial cognitive motivational studies that learning success and enhanced motivation is conditional on learners taking responsibility for their own learning, being able to control their own learning and perceiving that their learning success and failures are to be attributed to their own efforts and strategies rather than to factors outside their control. Each of these conditions is a characteristic of learner autonomy as it is described in applied linguistics.

However, comparatively speaking, there are few specific studies that are conducted on the relationship between motivation and language acquisition(LA) and perspectives of the studies on motivation and LA are narrow and in China there is little or no study that has been done on the correlation between motivation and autonomy. The study of language learning motivation in China has a much shorter history. Since 1990s, the field of foreign language teaching and research in China has been treating motivation as an independent variable (Lu Min 2009, p. 62). Some Chinese researchers have tried to identify Chinese language learners' motivation types. Wu, Liu and Jeffrey (1993) took the 
factor of motivation into account in their study of individual differences, finding that learning motivation of Chinese learners of English tended to be instrumental. Shi (2000) investigated the motivational types of Chinese learners and analyzed the relationship between motivation and learning achievement. He found out that the difference between the successful learners and less successful learners lies in that the former have stronger intrinsic motivation. Huang and Wen (2005) explored the components of motivation of non-English majors, finding that language valence is the greatest predictor of students' motivation. In addition, Chinese researchers have done correlational studies to investigate the relationship between motivation and leaning achievement (Zhou 1992), the relationship between motivation and learning strategies (Wen 1995, 2001, Wen \& Wang, 1996, Wen et. Al. 2000). We can see that the correlational studies involve a couple of variables, but few studies have been conducted to explore the internal structure and the relationship among a variety of variables related to L2 motivation and little or no study has been done on the correlation between motivation and learner autonomy.

\section{DisCUSSIONS}

In the practice of my teaching in the past years I have found out through my observation and communication with students that the lack of intrinsic motivation is one of the key factors that prevent students from working hard on English or other subjects. Most Chinese learners are not highly intrinsically motivated and autonomous, because almost all the students are studying for the exams, which corresponds to Hua's(1998) investigation that getting a certificate is the major motivation of Chinese learners. For some students, once they enter college by doing successfully at the Entrance Exam, they lose their definite goals and orientations, because they have been driven too much by the exams and too dependent on the teachers. Even when they are at the college level, what they care most is still how well they can do in the exams. Therefore, in recent years I have been thinking about what can be done to help students develop their autonomy and how to promote their intrinsic motivation.

In the past eight years since 2004, together with a group of teachers in my department (College English Department, DaLian University of Technology), we have been doing research on how to improve learner autonomy through strategy training, developing our own teaching materials and setting up a self-access center; and in 2006, we began to focus on the research of developing a "process syllabus" in the language classroom through negotiation with students and negotiation between students. Process means taking students through the various stages of producing language and it emphasizes the value of collaborative learning, leaner-centeredness, learner autonomy and shared decision making in the language classroom. In traditional syllabuses, the content is prescribed by syllabus writers before a course begins, therefore, traditional syllabuses are predictive documents because they set out what is to be taught. These syllabuses are product-oriented, which focus on the outcomes of instruction, i.e. the knowledge and skills to be gained by the learner. However, process syllabuses focus on the skills and processes involved in learning language and the learning experiences themselves rather than on the end products of these processes. An important characteristic of the process syllabus is that it is an infrastructure rather than a learning plan, with the syllabus designer no longer pre-selecting learning content, but providing a framework for teacher and learners to create their own on-going syllabus in the classroom (Breen, 1987a, p.166), , thus allowing for changing abilities, learning needs, and perceptions in the learners, without specifying particular content, methodology, lexis, structure, or grammar (Breen, 1987a, p.168). The process syllabus is a radically analytic syllabus. In its strong form at least, not only the content but the materials, methodology and types of assessment used in a course are not pre-determined but are negotiated between the instructor and the learners throughout the course. That is, learners help select course content and materials and provide input on how they want to be taught and assessed. Process syllabuses have therefore evolved "as a means of planning, implementing and evaluating negotiation in the classroom, and the decisions to which teachers and students may jointly arrive" (Breen \& Littlejohn, 2000, p.2). It distinguishes itself from conventional, content syllabuses by identifying classroom decisions as potentials for negotiation whereby teacher and students together can evolve and work through the actual curriculum of the classroom group (Breen \& Littlejohn, 2000, p.29). The nature of a process syllabus is, through ongoing process of negotiation, to help students make clear of their alternative assumptions and interpretations, identify the range of achievements and difficulties in the work and reveal their preferences and alternatives in ways of working. We believe that negotiating a syllabus will help to take into account the wants and needs of the students and promote learner motivation, and more importantly it will encourage students to take much more responsibility for their own learning, in this sense, their learner autonomy will be greatly improved.

In China, working in the context of a centralized educational system which prescribes curricula, authorizes textbooks and sets external exams, students are used to taking the teacher as the authority and expert in handling the textbooks and making decisions about what they should learn and how they should learn. For teachers, it is easier to produce a well-planned, neatly packaged curriculum by deciding well in advance exactly what is to be studied and where and when and how it is to be presented. However, we trust that when students are involved in the process of decision-making, options and choices and when they can have their say through negotiation and when they become aware of learning procedures, they will learn best, which concurred with Curran, who expressed this as a belief that 'People learn best from utterances in which they have a strong personal stake or "investment"' (2000, cited in Pnina Linder). Therefore, it is important for teachers to provide the circumstances and contexts for learners to help them rather 
than prevent them from exercising their autonomy so that they can take charge of the whole or part of their language learning.

Through the research on the development of process syllabus we found out that students are highly motivated through making decisions for themselves and are more responsible for their learning and motivation is a prerequisite for learning and responsibility development. The learner is not simply a passive recipient in the process. Knowles (1990) argues that adults should have a strong voice in their education and in the way they learn. They are likely to be-or to wish to be-self-directed learners and usually need to be assured about the purpose of the learning. He also argues that adult learners move from dependency to self-directedness and use their life experience to enhance learning. Furthermore, learners were also positive in accepting responsibility for their own learning. These were also the findings of Dam and Gabrielsen when they investigated the extent to which young learners were capable of making decisions about the content and processes of their own learning (Nunan, 1996). We believe that in the process of negotiation and collaboration with group members when they are making decisions about the aims, the content, the ways and the evaluations, especially when they are presenting something to another group/class, it called for greater responsibility to their own group and led to increased motivation and greatly improved accuracy. The success of each group's presentation was measured by the response and feedback of the other groups; thus there was a measure of in-built evaluation and a test of how much had been learned. We found out when learners are becoming more autonomous in making decisions concerning why to learn, what to learn and how to learn, the intrinsic motivation of learners is stimulated, they are able to identify with the goals of learning and more willing to take responsibility for the outcome. In turn, a large scope for student making decisions for themselves and autonomy generates intrinsic motivation.

\section{CONCLUSION}

Conventionally, it is assumed that it is the teacher's role to make decisions with regard to purposes of the work, focus of content, ways of undertaking the work and evaluation of students' performances, both covertly as part of planning and classroom management and through overt instructions at key moments in a lesson. However, through two years' experiment and several years' learner autonomy research, there are several justifications for raising such decisions to the level of overt negotiation with students. Student-initiated teaching combined with syllabus negotiation brought all the learners to be more open-minded to other's ideas, thoughts, suggestions and even criticisms, because greater control over the learning process, resources and language cannot be achieved by each individual acting alone according to his or her own preferences. In the classroom group, genuine autonomy has to be exercised in an interdependent way. This practice of negotiated syllabus helps students to break out of the cocoon of dependence on the teacher. Once this has happened, negotiation inevitably becomes an ongoing process. It is thus that the foundations of autonomy are laid. The process of negotiation functions as managing teaching and learning as group experience and students are highly motivated when they are given the power to make the decisions, options and choices by themselves, when their wants and needs are taken into account and when they have their voices heard by others.

\section{REFERENCES}

[1] Anderman, E.M., \& Wolters, C. A. (2006). Goals, Values, and Affect: Influences on student motivation. In P. A. Alexander, \& P. H. Winne (Eds.), Handbook of Educational Psychology (pp. 369-389). Mahwah, NJ: Lawrence Erlbaum.

[2] Benson, P., (2005). Teaching and Researching Autonomy in Language Learning. Beijing: Foreign Language Teaching and research Press.

[3] Biehler, R. F., (1993). Psychology Applied to Teaching, 7th edition. Houghton Mifflin Company.

[4] Breen, M. P. and Littlejohn A. (2000). Introduction and Overview: The significance of negotiation. In M. P. Breen and A. Littlejohn (eds.) Classroom Decision-Making Negotiation and process syllabus in practice, pp. 5-38. Cambridge: Cambridge University Press.

[5] Breen, M.P. (1987a). Contemporary paradigms in syllabus design, part I. Language Teaching, 20/2, 157-174.

[6] Brooks, A. and Grundy, P. (1988). Introduction: Individualization, Autonomy and English for Academic Purposes. In A. Brookes and P. Grundy (eds.) Individualization and Autonomy in Language Learning, pp.1-11. Modern English Publications in association with the British Council.

[7] Deci, E. L. \& Ryan, R. M. (1985). Intrinsic Motivation and Self-Determination in Human Behavior. New York, NY: Plenum Press.

[8] Deci, E. L. \& Ryan, R. M.( Eds.) (2002). Handbook of Self-determination. Rochester, NY: University of Rochester Press.

[9] Dickinson, L. (1987). Self-instruction in Language Learning. Cambridge: Cambridge University Press.

[10] Dickinson, L. (1995). Autonomy and motivation: A literature review. System 23: 165-74.

[11] Dörnyei, Z. (2005). Teaching and Researching Motivation. Beijing: Foreign Language Teaching and research Press.

[12] Gardner, R. C. and Lambert, W. E. (1959). Motivational variables in second language Learning. Canadian Journal of Psychology 13: 266-72.

[13] Gardner, R. C. and Lambert, W. E. (1972). Attitudes and Motivation in Second Language Learning. Newbury House, Rowley, MA.

[14] Holec, H. (1981). Autonomy and Foreign Language Learning. Oxford: Oxford Pergamon.

[15] Hua HuiFang. (1998). A Study on English Learning Motivation and Strategy. Foreign Language World, 3, 44-47.

[16] Huang Hong'an \& Wen Weiping. (2005). Empirical Studies on Component Factors of Undergraduates' English Learning Motivation. Foreign Language Teaching, 3, 30-37. 
[17] nowles, M.S.(1975). Self-directed Learning: a Guide for Learners and Teachers. New York: Cambridge, The Adult Education Company.

[18] Linder, P. (2000). Is a negotiated syllabus feasible within a national curriculum? In P. Breen and A. Littlejohn(eds.) Classroom Decision-Making Negotiation and process syllabuses in practice, pp.94-107. Cambridge: Cambridge University Press.

[19] Little, D. (1990). Autonomy in Language Learning. London: CILT.

[20] Lu Min.(2009). A Research on Foreign Language Learning Motivation in Classroom. Beijing: China Social Sciences Prss.

[21] Noel, K. A., Pelletier, L. G., Clement, R., \& Vallerand, R. J. (2000). Why are you learning a second language? Motivational orientations and self-determination theory. Language learning, 50(1), 57-85.

[22] Noels, K.A. (2001b). Learning Spanish as a second language: Learners' orientations and perceptions of their teachers' communication style. Language learning, 51, 107-144.

[23] Nunan, D. (1988). Syllabus Design. Oxford: Oxford University Press.

[24] Nunan, D. (1996). Towards autonomous learning: some theoretical, empirical and practical issues. In R. Pemberton \& Edwards S.L. Li (eds.) Taking Control Autonomy in Language Learning, pp.13-26. Hong Kong: Hong Kong University Press.

[25] Pennycook, A.(1997). Cultural Alternatives and Autonomy. In P. Benson and P. Voller(eds) Autonomy and Independence in Language Learning. London: Longman.

[26] Pintrich, P.R., \& Schunk, D.H.(2002). Motivation in Education: Theory, research, and applications (2nd edition) Englewood Cliffs, NJ: Prentice Hall.

[27] Shi Yongzhen. (2000). Report on a Survey of College English Learners' Motivation. Foreign Language Teaching, 4, 8-11.

[28] Spratt, M., Humphreys, G.,\& Chan, V. (2002). Autonomy and motivation: Which comes first? Language Teaching Research, 6 , 245-266.

[29] Ushioda, E. (1996). Developing a dynamic concept of motivation. In T. Hickey, \& J. Williams (Eds.), Language, Education and Society in a Changing World (239-245). Clevedon: Multilingual matters.

[30] Weiner, B. (1985). An Attributional Theory of Motivation and Emotion. New York: Springer-Verlag.

[31] Wenden, A. (1991). Learner Strategies for Learner Autonomy. Englewood Cliffs: Prentice Hall.

[32] Wen Qiufang. (1995). Different Learning Strategies between Successful and Unsuccessful Learners. Foreign Language Teaching and Research, 3, 61-66.

[33] Wen Qiufang. (2001). Developmental Patterns in Motivation, Belief s and Strategies of English Learners in China. Foreign Language Teaching and Research, 2, 105-110.

[34] Wen Qiufang \&Wang Haixiao.(1996). Relationship of Learner Variables to Scores on College English Test—Band 4. Foreign Language Teaching and Research, 4, 33-39.

[35] Wen Qiufang, Wang Haixiao, Le Meiyun, Ding Yanren and Wang Wenyu.(2000). Post-project Report on the Ninth Five-Year Plan Social Science Project: Developmental Patterns in Motivation, Belief s and Strategies of English Learners in China.

[36] Wu Yi'an, Liu Ruiqing and Jeffrey. (1993). Learner factors and language learning achievement: a survey. Foreign Language Teaching and Research, 1, 36-46.

[37] Zhou Yan. (1992). Language Learning and Psyehosocial factors. Papers from Tianjin Conference of ELT in China, Beijing: Foreign Language Teaching and Research Press, 49-75.

Zejun Ma was born in FuXin, LiaoNing province, China in 1970. She received her Master degree in linguistics from DaLian University of Foreign Languages, China in 2004. She was sponsored by the Chinese Education Ministry as a visiting scholar to do independent research in the field of pragmatics and discourse in Cardiff University in UK for a year from 2008 to 2009.

She is currently an associate professor in the School of Foreign Languages, DaLian University of Technology, DaLian, China. Her research interests include language teaching, pragmatics and discourse.

Ruixue Ma is currently a lecturer in the School of Foreign Languages, DaLian University of Technology, DaLian, China. Her research interests include language teaching, second language acquisition and intercultural communication. 